\title{
The Academic Library's Contribution to Student Success: Library Instruction and GPA
}

\author{
Ula Gaha, Suzanne Hinnefeld, and Catherine \\ Pellegrino
}

Preliminary data from this paper were presented as a poster session at the annual meeting of the Academic Libraries of Indiana in Greencastle, Indiana on May 6, 2016 and also in a conference session at the joint conference of Georgia COMO and the Southeastern Library Association in Athens, Georgia on October 6, 2016.

This study examines the relationship between library instruction and graduating students' four-year cumulative grade point averages for the classes of 2012-2015. After normalizing the GPAs by departments to account for differences in departmental grading, a two-tailed t-test indicated a statistically significant increase in GPA among graduating students who were enrolled in classes in which at least one library instruction session was held $(n=1,265)$ over students who were enrolled in no classes with library instruction $(n=115)$. Librarians are using the results to demonstrate the relationship between the library and student success, and to promote library instruction on campus.

\section{Introduction}

As the academic library community has seen in the half-decade since the establishment of the Association of College and Research Libraries' (ACRL) Value of Academic Libraries project, librarians at institutions of higher education face increased pressures to demonstrate their contributions to various measures of student success within their institutions. ${ }^{1}$ In that context, the authors encountered Krista Soria, Jan Fransen, and Shane Nackerud's groundbreaking work linking students' library experience with their educational outcomes at the University of Minnesota, and were troubled by their finding that course-integrated library instruction in students' first year of undergraduate study was negatively correlated with their first-year grade-point average. ${ }^{2}$ Knowing that both Shun Han Rebekah Wong and Dianne Cmor, as well as Melissa Bowles-Terry,

Ula Gaha is Reference and Instruction Librarian at Saint Mary's College, Notre Dame, Indiana, e-mail: ugaha@saintmarys.edu; Suzanne Hinnefeld is Collection Development Librarian at Saint Mary's College, Notre Dame, Indiana, e-mail: shinnefe@saintmarys.edu; Catherine Pellegrino is Reference and Instruction Librarian at Saint Mary's College, Notre Dame, Indiana, e-mail: cpellegr@saintmarys.edu. (C2018 Ula Gaha, Suzanne Hinnefeld, and Catherine Pellegrino, Attribution-NonCommercial (http://creativecommons. org/licenses/by-nc/4.0/) CC BY-NC. 
have documented positive correlations between library instruction and students' GPA, the authors wondered if variability in disciplinary grading standards accounted for the negative correlation between instruction and GPA in the Minnesota study. ${ }^{3}$ In other words, perhaps majors with more rigorous grading standards were more likely to use library instruction, while majors with "easier" grading were less likely to use library instruction, resulting in an effect that looked like a negative correlation, but was actually an artifact of disciplinary grading standards.

Differential grading standards in different disciplines is a well-documented phenomenon in higher education: B. Curtis Eaton and Mukesh Eswaran examined data from three universities in Canada and found a wide variation in average grades by discipline. However, that variation did not necessarily follow the stereotype of higher grades in humanities departments and lower grades in the sciences; at one university, "Low Marks" departments included History and English, while "High Marks" departments included Physics and Mechanical Engineering. ${ }^{4}$ In a more recent study in the United States, Stuart Rojstaczer and Christopher Healy reviewed grading norms of more than 200 institutions of higher education between 1940 and 2009, and found that faculty at institutions that emphasized science and engineering tended to give lower grades than faculty at institutions that emphasized the liberal arts. ${ }^{5}$ The study reported here was the authors' attempt to test the hypothesis that controlling for differential grading standards in the statistical analysis clarifies the relationship between library instruction and students' GPAs with data available at a much smaller campus than the University of Minnesota. By accounting for differences in GPAs across students' majors, this study seeks to determine whether library instruction was positively or negatively correlated with students' four-year cumulative GPAs, a measure of overall student success.

Four-year cumulative grade point average is not the only measure of student success, nor is it necessarily a measure of student learning. While many factors might be considered as measures or indicators of students' success or learning-employment or salary after graduation, analysis of artifacts of student work, scores on standardized exams, even measures of life satisfaction-GPA is one measure that is already quantitative, and to some degree standardized. In addition, librarians and faculty have ready access (with appropriate safeguards to assure confidentiality) to students' GPA data at their own institutions. For these reasons, the authors agree with Bowles-Terry that while GPA is "an imperfect measure of learning and achievement," it nevertheless can be understood as an acceptable proxy for student success. ${ }^{6}$

\section{Literature Review}

The three studies cited above that launched this research project-Soria et al., Wong and Cmor, and Bowles-Terry-each include extensive reviews of the literature surrounding the intersection of library services, particularly instruction, and student success. Additionally, Joseph R. Matthews's Library Assessment in Higher Education looks more broadly at what had been written about assessing and evaluating library services and collections prior to its publication in 2007. ${ }^{7}$ Before the publication of the Association of College and Research Libraries' Value of Academic Libraries: A Comprehensive Research Review and Report in 2010, Matthews's book was the most comprehensive review of the library assessment literature. ${ }^{8}$ In particular, Matthews's fifth chapter ("Assessment of the Library's Contribution to the Educational Process") examines a wide variety of studies on library services that are generally viewed as essential to students' education, including reference, library instruction, and information literacy programs. Rather than duplicate the work of these previous reviews here, this literature review focuses specifically on what the library research community knows about the intersection of 
library instruction and student success, with a particular emphasis on studies that have examined students' majors or disciplines as an element of their research design.

Several large-scale studies have established that library instruction is correlated with increased grade-point averages (GPAs) under certain conditions. Melissa BowlesTerry found that library instruction was positively correlated with students' GPAs when the instruction was repeated at different levels in the curriculum; specifically, when it was offered in upper-level courses. ${ }^{9}$ In her study of almost 4,500 graduating seniors' academic transcripts, Bowles-Terry demonstrated the reach of library instruction at her institution: she found that three fourths of the students in the study received instruction in their first year of college. The extent of first-year instruction at her institution provides the foundation of her argument that a library instruction program needs clearly defined goals for students at every level of study, and a scaffolded approach to student mastery of specific information literacy skills at each level. Her work suggests that librarians need to design more cohesive and non-repetitive information literacy curricula by differentiating between lower-division and upperdivision learning objectives.

Library instruction also correlates with increased GPAs when students receive more than a baseline level, defined as one or two sessions, of instruction. Shun Han Rebekah Wong and Dianne Cmor evaluated over 8,000 undergraduate and graduate transcripts at Hong Kong Baptist University, and found a positive correlation between exposure to multiple library instruction workshops and higher GPAs; however, that correlation only occurs when a minimum amount of library instruction is provided. One or two library workshops had little correlation with higher GPAs, but three or more workshops had a stronger correlation. ${ }^{10}$ In contrast with Wong and Cmor's work, Felly Chiteng Kot and Jennifer Jones found a small but significant gain in first-term GPA in students who participated in a variety of library interactions, as compared with students who did not. ${ }^{11}$ Most notable among those interactions were research clinics, which were one-hour workshops on various topics relating to library research, rather than the course-integrated instruction sessions described in Bowles-Terry and Wong and Cmor's research. Kot and Jones found a statistically significant increase in GPA with attendance at just a single research clinic. Their work is notable for their use of propensity score matching to reduce self-selection bias in their sample. The authors paired students who used library resources with students with similar characteristics (e.g., gender, race, campus experiences, etc.) who did not. This strategy allowed them to mimic the effect of treatment and control groups by sorting roughly equivalent groups of students into both the "treatment" (used library resources) and "control" (did not use library resources) groups. ${ }^{12}$

These three studies, each demonstrating a positive correlation between participation in library instruction and students' graduating GPAs, make the negative correlation demonstrated by Krista Soria, Jan Fransen, and Shane Nackerud that much more surprising. In the largest study of its kind within the United States, Soria and her co-authors examined the intersection of multiple library resources and services with student retention and success at the University of Minnesota. ${ }^{13}$ They studied over 5,300 first-year, non-transfer undergraduate students; the study is particularly groundbreaking for its extensive controls for demographic characteristics, pre-college academic preparation, and campus experiences. The authors found that students who utilized at least one library resource or service-e.g., checking out books, logging into electronic journals, or using chat reference- at least once during their first semester had a higher first-term GPA, and higher fall-to-spring semester retention, in comparison to non-library users. Students who enrolled in a credit-bearing library research course also had a higher fall-to-spring retention rate. However, their data also reveal that 
participation in a course-integrated library instruction session was associated with a decrease of 0.08 points (on a four-point scale) in students' first-year GPAs. ${ }^{14}$ Although the practical significance of such a small differential is minor, it still represents a negative correlation. While the authors note challenges with measuring the effectiveness of library instruction, they offered no specific explanation for this negative correlation, prompting the current study. ${ }^{15}$

While many researchers have examined the relationship between GPA and kinds of library interaction that are not instruction-based (e.g., using books or online resources, reserving study rooms), those studies fall outside the scope of this review of the literature. Nevertheless, one exception is the work of DeeAnn Allison at the University of Nebraska-Lincoln. ${ }^{16}$ Because Allison took into account students' large-scale disciplines of study (humanities, social sciences, or STEM disciplines), it is included here for its relationship to this current study's methodology, which accounts for students' majors. Allison found the strongest correlation between library use and GPAs in students who majored in humanities disciplines. She also took a different approach to the question of library use and students' GPAs by reversing the independent and dependent variables in one aspect of her study. She found that undergraduates with higher than average GPAs accessed electronic resources from off campus and checked out print books more often than students with lower than average GPAs. Allison cautions, however, that "it is difficult to say whether library use makes good students, or library use is a characteristic of a good student."17

One other study already cited above also sorted student participants into groups by their majors or larger fields: in Wong and Cmor's work, it was precisely the separation of participants by majors that enabled the authors to discover that more than two instruction sessions increased the likelihood of a positive correlation between the instruction and students' GPAs. ${ }^{18}$ An earlier research project by Wong, with co-author T.D. Webb, also divided participants by their majors and compared GPAs of students who did and did not check out materials from the library only within the same department, rather than across departments. ${ }^{19}$ By comparing only students within the same department, Wong and Webb were motivated by the same concern as the research reported here: a desire to account for different disciplinary grading standards. Wong and Webb's approach is appropriate for the very large data sets available at a large research university, where each major might have hundreds of student graduates within a few years. The current study's approach of normalizing GPAs works with the smaller data sets available at a smaller institution, and allows researchers to compare GPAs across an entire college or university. None of the research published to date duplicates the methodology presented here, which seeks to neutralize the differences between grading standards in different departments and disciplines, so that differences in students' GPAs might be more directly attributable to their experience with library instruction, rather than an artifact of varying grading standards across the college.

\section{Methods}

After the project was approved by the Saint Mary's College Review Board for research with human subjects, the authors worked with the Office of Institutional Research and Assessment to collect data on students' transcripts and cumulative grade-point averages, beginning with a list of all courses that had at least one library instruction session from Fall 2008 through Spring 2015. This list included every course with library instruction taken by students graduating with the classes of 2012 through 2015. The staff of the Office of Institutional Research and Assessment then ran that list of courses against the transcripts of students graduating with the classes of 2012 through 2015. 
The list of graduating students included 1380 individuals. Students who matriculated between Fall 2008 and Fall 2011, but did not graduate, were excluded from the study. Students who took more than four years to graduate were included as part of the class with which they graduated. Because $92.6 \%$ of graduates at Saint Mary's College complete their degree in four years, the authors simplified the analysis by not attempting to adjust the collection methods to account for the relatively small number of students who took more than four years to graduate..$^{20}$ What resulted was a list of anonymized identification numbers for individual students; those students' majors (coded as "Major1," "Major2," etc. to preserve students' anonymity); the number of courses those students were enrolled in that had a library instruction session; and students' four-year cumulative GPAs.

It is important to note that these data indicate whether students were enrolled in a course that had a library instruction session, not whether each student actually attended the library instruction session. Since the research targeted courses and instruction sessions that had already occurred, it was not logistically possible to measure actual student attendance. Experience at Saint Mary's College indicates that the attendance rate for course-related instruction sessions is sufficiently high (generally no more than 2-3 absent students out of a class enrollment of 20-30) that it should not materially affect the statistical analysis. The authors' decision to simplify the analysis matches both BowlesTerry's and Soria et al.'s methodologies, in which both sets of researchers assumed that students enrolled in courses with library instruction attended that instruction. ${ }^{21}$

Before looking for a correlation between enrollment in courses with library instruction and students' GPAs, the authors controlled for differences in departmental grading by normalizing GPAs by majors. This was accomplished by calculating a mean GPA for each major, and dividing each major's mean GPA into the highest departmental mean GPA, resulting in a normalizing factor ratio greater or equal to 1 for each major. Each student's GPA was then multiplied by the normalizing factor for their major. For example, when the mean GPA for Major3 was divided into the maximum mean GPA, the result was a factor ratio of 1.104. Each student in Major3 had her GPA multiplied by 1.104 to account for the difference in departmental grading between this major and the highest (or "easiest") major. This resulted in a list of students' GPAs that were effectively "curved" for the differences in departmental grading across the institution. Normalizing the students' GPAs enabled comparisons among students across all departments at the college on a level playing field; a student's normalized GPA could be compared with other students' normalized GPAs without the grading practices of their disciplines affecting the comparison.

The null hypothesis was that the normalized GPAs of students who took no classes with library instruction were equal to the GPAs of students who enrolled in at least one class with a library instruction session. To test the null hypothesis, the authors performed a two-tailed t-test on normalized GPAs for students who had no library instruction $(n=115,8.3 \%)$ versus students who took at least one course with library instruction session $(n=1,265,91.7 \%)$. The two-tailed t-test is a statistical measure that tests whether the means of two populations are equal, or whether the mean of one population is greater or lesser than that of the other, and also whether that difference is too great to be attributed to random chance and variation in the data (i.e., statistically significant). When applied to the data, the two-tailed t-test measured whether the normalized GPAs of students who took classes with library instruction were greater, lesser, or equal to the normalized GPAs of students who did not take classes with library instruction.

Prior to comparing the means with the t-test, the authors first determined with an F-test that the two populations had equal variances. The results from the F-test indicated which t-test to perform. Because the two populations had equal variances, the two-tailed t-test was the appropriate choice. 


\begin{tabular}{|c|c|c|}
\hline \multicolumn{3}{|c|}{ TABLE 1 } \\
Range of Student Participation in Library Instruction \\
\hline $\begin{array}{c}\text { Number of Courses with Library } \\
\text { Instruction }\end{array}$ & $\begin{array}{c}\text { N } \\
\text { (Number of Students) }\end{array}$ & Percent \\
\hline 0 & 115 & $8.3 \%$ \\
\hline 1 & 321 & $23.3 \%$ \\
\hline 2 & 360 & $26.1 \%$ \\
\hline 3 & 292 & $21.2 \%$ \\
\hline 4 & 159 & $11.5 \%$ \\
\hline 5 & 83 & $6.0 \%$ \\
\hline 6 & 40 & $2.9 \%$ \\
\hline 7 & 3 & $0.2 \%$ \\
\hline 8 & 7 & $0.5 \%$ \\
\hline Total: & $\mathbf{1 , 3 8 0}$ & $\mathbf{1 0 0 \%}$ \\
\hline
\end{tabular}

\section{Results}

The first thing the research demonstrated was the extent of the instruction program's reach within the institution, information that was inaccessible prior to the data collection.

Table 1 shows the number of courses with library instruction that students from the graduating classes of 2012-2015 completed. As the table demonstrates, a large majority of graduates took one to three courses with library instruction, and very few-only 115 students, or $8.3 \%$ - had no contact with library instruction. The data also demonstrated the range of possible GPAs among students who graduated from the institution: prior to the normalizing process (which raised nearly all students' GPAs considerably), GPAs ranged from a high of 4.0 to a low of 2.187 . Two hundred twenty-five students $(16.3 \%)$ had GPAs of less than 3.0, and 503 students (36.4\%) had GPAs of greater than 3.5.

\begin{tabular}{|c|c|c|c|}
\hline \multicolumn{4}{|c|}{ TABLE 2} \\
Average Normalized GPAs by Number of Library Instruction Sessions \\
\hline $\begin{array}{c}\text { Number of Library } \\
\text { Instruction Sessions }\end{array}$ & $\begin{array}{c}\text { Average of } \\
\text { Normalized GPAs }\end{array}$ & $\begin{array}{c}\text { Standard } \\
\text { Deviation }\end{array}$ & N \\
\hline 0 & 3.62 & 0.347 & 115 \\
\hline 1 & 3.73 & 0.330 & 321 \\
\hline 2 & 3.68 & 0.324 & 360 \\
\hline 3 & 3.69 & 0.339 & 292 \\
\hline 4 & 3.68 & 0.347 & 159 \\
\hline 5 & 3.66 & 0.359 & 83 \\
\hline 6 & 3.69 & 0.276 & 40 \\
\hline 7 & 3.76 & 0.295 & 3 \\
\hline 8 & 3.78 & 0.308 & 7 \\
\hline $\mathbf{1 - 8}$ & $\mathbf{3 . 7 0}$ & $\mathbf{0 . 3 3 3}$ & $\mathbf{1 , 2 6 5}$ \\
\hline
\end{tabular}


Students who did not take any classes with library instruction had the lowest average normalized GPAs, 3.62 (see table 2).

This compares to an average normalized GPA of 3.73 for students who enrolled in one course with library instruction, and 3.70 for all students who took one or more courses with library instruction. Fitting a smooth curve through normalized average GPAs for students with zero to four courses with library instruction illustrates the increase in GPA for students in these most highly populated groups (see figure 1).

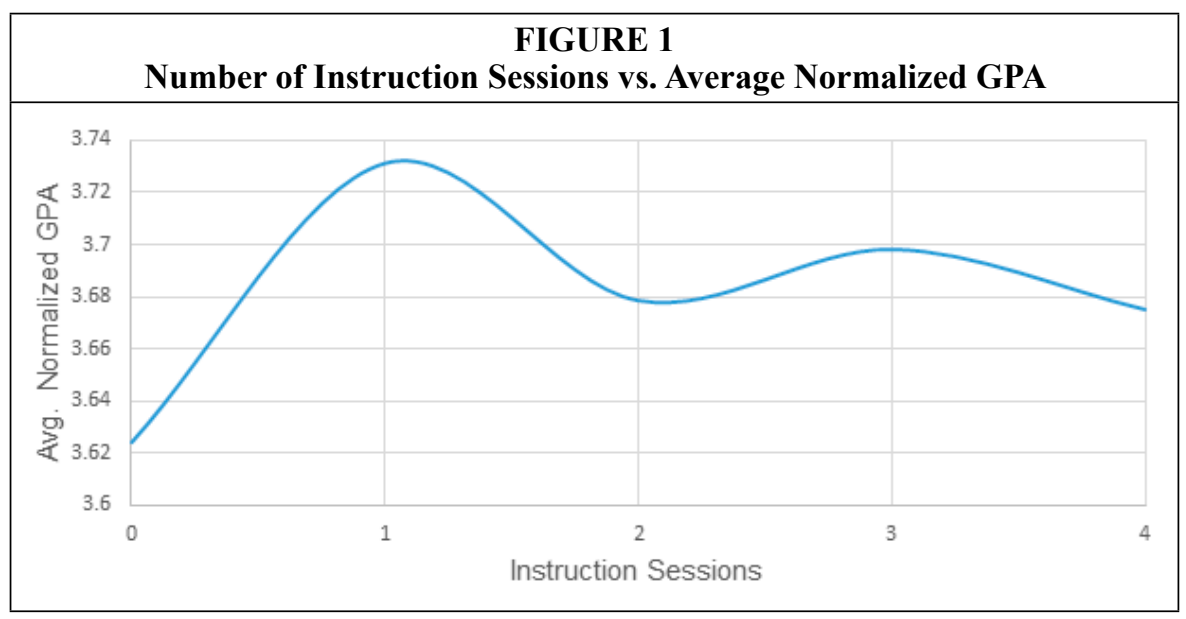

After four courses with library instruction, the sample sizes drop dramatically; the groups with seven and eight courses with library instruction include only three and seven students, respectively. The authors hypothesize that the high GPAs in these two groups are the result of outlier data points: students with unusually high GPAs. If those two groups had had larger sample sizes, those outlier data points might not have skewed the averaged normalized GPAs so strongly. Further research, with larger sample sizes, is necessary to confirm this hypothesis.

As table 3 shows, the t-tests for equality of means reject the null hypothesis that the GPAs of students who enrolled in no classes with library instruction were equal to the GPAs of students who enrolled in at least one class with library instruction. In other words, the authors observed a statistically significant increase in the normalized

\begin{tabular}{|l|c|c|c|c|c|c|c|}
\hline \multicolumn{7}{|c|}{ TABLE 3 } \\
\hline $\begin{array}{c}\text { Means } \\
\text { Compared }\end{array}$ & t & df & $\begin{array}{c}\text { Sig. } \\
\text { (2-Tailed) }\end{array}$ & $\begin{array}{c}\text { Mean } \\
\text { Difference }\end{array}$ & $\begin{array}{c}\text { Std. } \\
\text { Error } \\
\text { Difference }\end{array}$ & \multicolumn{2}{c|}{$\begin{array}{c}\text { 95\% Confidence } \\
\text { Interval of the } \\
\text { Difference } \\
\text { Lower }\end{array}$} \\
Upper \\
\hline 0 vs 1 & -2.94 & 434 & 0.00346 & -0.107 & 0.0364 & -0.178 & -0.0355 \\
\hline 0 vs 2 & -1.54 & 473 & 0.124 & -0.0544 & 0.0353 & -0.124 & 0.0150 \\
\hline 0 vs 3 & -1.97 & 405 & 0.0494 & -0.0740 & 0.0376 & -0.148 & -0.000193 \\
\hline 0 vs 4 & -1.20 & 272 & 0.232 & -0.0509 & 0.0425 & -0.135 & 0.0327 \\
\hline $\begin{array}{l}0 \text { vs } 1 \text { or } \\
\text { more }\end{array}$ & -2.21 & 1,378 & 0.0274 & -0.0719 & 0.0325 & -0.136 & -0.00803 \\
\hline
\end{tabular}


GPAs of students who were enrolled in at least one class with a library instruction session. The confidence intervals listed in Table 3 indicate the precision of the differences of the means.

Because this research accounted for differences in grading among students' majors, and the data set therefore included students' (coded) majors, the authors also investigated whether, within a specific major, students who had courses with library instruction graduated with higher GPAs than students who did not. Unfortunately, despite pooling data from four graduating classes, the small size of the institution and the reach of the instruction program hampered this analysis. Few majors included sufficient numbers of students who had no library instruction to make the analysis possible. Of the 40 majors offered at Saint Mary's, 20 could not be evaluated for the impact of library instruction on GPA at the major level because there were fewer than two students who had no contact with library instruction. Evaluating these majors would have resulted in degrees of freedom of less than zero, and the resulting t-test calculation would have been impossible.

Of the 20 majors for which a t value could be calculated, four majors demonstrated statistical significance at the $\mathrm{p} \leq 0.05$ level. For these four majors, students who took at least one class with library instruction had statistically significant higher GPAs than students in the same major who were enrolled in no classes with library instruction. Although the data only supported this kind of analysis with a small number of majors, this result nevertheless suggests that the positive correlation between library instruction and GPA also exists within certain majors, as well as across majors.

\section{Discussion}

Many instruction librarians are familiar with the student complaint, "I've already heard all of this before!" Yet prior to collecting the data, librarians at Saint Mary's College did not know how many students had indeed attended multiple library instruction sessions, what the maximum number of instruction sessions attended was, or even how many students graduated with no library instruction at all. The data presented in table 1 show that a very large majority $(n=973,70.5 \%)$ of the seniors graduating between 2012 and 2015 took one to three courses that incorporated library instruction sessions, with a small subset $(n=7,0.5 \%)$ of students enrolled in eight courses in which library instruction sessions had been held, and an even smaller subset $(n=3,0.2 \%)$ who had taken seven courses. Ninety-two percent $(n=1265)$ of seniors graduating between 2012 and 2015 were enrolled in at least one course with a library instruction component. These numbers provide context for the reach and scope of the instruction program, while also serving as a useful reminder that at least a small number of students can truthfully complain, "but I've heard this all before!"

The data illustrate a small but statistically significant increase in the four-year cumulative GPAs of students who were enrolled in classes in which at least one library instruction session was held. While correlation does not indicate causation, the t-tests in this statistical analysis indicate that the increase in GPA is not due to chance. Moreover, the relatively large sample size of 1,380 students contributes to the authors' confidence in the correlation. When each student's GPA was normalized to account for differences in grading rigor between departments and majors, the results did not display the negative correlation that Soria et al. found in their data at the University of Minnesota. The evidence indicates, therefore, that the relationship between library instruction and GPA - at least at this institution - is not due to departments with "harder" grading standards that coincidentally happened to have fewer courses with library instruction.

There were, of course, several limitations with the research reported here. The first is that the data did not fully account for the $6.5 \%$ of students who take more than four 
years to graduate; for some of these students, this analysis may have under-calculated the number of courses they took that had library instruction. A more careful analysis would have included a list of courses for six or more years prior to the students' graduation year, and future studies may be able to incorporate this more nuanced analysis. This research also did not account for actual student attendance at library instruction; if a student missed class on the day of the library instruction session, that student was still counted as having attended the session by virtue of being enrolled in the course. It is hard to imagine a feasible strategy for overcoming this limitation, because taking attendance at every instruction session would be tremendously burdensome for librarians and would significantly reduce students' anonymity. While coding students' majors reduced the risk of reverse-identification of individual students, it also made it impossible to determine which departments saw the greatest increase in students' GPAs with library instruction. Larger data sets would increase the number of majors with very small numbers of student participants, and make it possible for researchers to view the data with actual department names, rather than codes. Finally, the authors recognize that four-year cumulative GPA is not a perfect proxy for "student success." While there are many definitions of student success, GPA is one that is widely recognized, easily quantifiable, and readily available at many, if not all, institutions of higher education.

\section{Conclusions}

The results have been useful both locally on the Saint Mary's College campus, and also in the wider conversation about academic libraries and student outcomes, because they show a real, statistically valid connection between library instruction and students' long-term academic achievement, as represented by their grade-point averages. The results also provide greater context for the negative correlation that Soria et al. found at the University of Minnesota, and suggest that disciplinary grading standards are yet another among the many factors researchers need to take into account when planning research design. Data like those described here can be used by librarians to demonstrate the value of their work in tangible terms that communicate to administrators, to advocate for additional resources, and to persuade faculty of the benefits of library instruction to their students. On this campus, the next steps will also include working to build consistent and tiered instruction in departments where a large number of courses have instruction, in order to reduce the effect of "I've heard this before!"

One of the advantages of conducting research such as this is that librarians do not have to collect additional data beyond what the institution already tracks and stores. After receiving IRB approval and safeguarding participants' privacy by removing student identification numbers and anonymizing the major codes, researchers can tap into a source of data that exists on all college and university campuses. Similar studies could easily be performed across a variety of campuses, and indeed, several have already been done, as documented above in the review of the literature.

Future research could control for both students' demographics and pre-college preparation (as Soria et al. did so thoroughly in their work at the University of Minnesota), as well as students' majors and departmental grading standards. The authors would also like to repeat this study with a larger set of student data to investigate whether students' GPAs truly do increase dramatically with large amounts of library instruction, as the data reported here appear to suggest, or whether that increase was a statistical anomaly that disappears with a larger data set. A larger data set would also increase the number of individual majors with enough data points to perform t-tests on students within that major. The authors' hope is that future research on this 
campus, or on campuses with larger undergraduate student bodies, would help to clarify the extent and range of the correlation between library instruction and graduating students' grade point average.

\section{Acknowledgements}

The authors gratefully acknowledge the assistance and contributions of Daniel Flowers, Director of Institutional Research and Assessment and Todd Norris, College Registrar.

\section{Notes}

1. Association of College and Research Libraries, "ACRL Value of Academic Libraries," accessed October 28, 2016, http://www.acrl.ala.org/value/ .

2. Krista M. Soria, Jan Fransen, and Shane Nackerud, "Library Use and Undergraduate Student Outcomes: New Evidence for Students' Retention and Academic Success," portal: Libraries and the Academy 13 (Apr. 2013): 147-164, accessed April 21, 2017, doi: 10.1353/pla.2013.0010.

3. Shun Han Rebekah Wong and Dianne Cmor, "Measuring Association between Library Instruction and Graduation GPA," College and Research Libraries 72 (Sept. 2011): 464-473, accessed October 28, 2016, doi: 10.5860/crl-151; Melissa Bowles-Terry, "Library Instruction and Academic Success: A Mixed-Methods Assessment of a Library Instruction Program," Evidence Based Library and Information Practice 7 (2012): 82-95, accessed April 21, 2017, doi: 10.18438/B8PS4D.

4. B. Curtis Eaton and Mukesh Eswaran, "Differential Grading Standards and Student Incentives," Canadian Public Policy / Analyse de Politiques 34 (June 2008), 222, accessed April 21, 2017, doi: 10.3138/cpp.34.2.215.

5. Stuart Rojstaczer and Christopher Healy, "Where A Is Ordinary: The Evolution of American College and University Grading, 1940-2009," Teachers College Record 114 (2012): 1-23, accessed April 21, 2017.

6. Bowles-Terry, "Library Instruction and Academic Success," 84. 2007)

7. Joseph R. Matthews, Library Assessment in Higher Education, (Westport, CT: Greenwood,

8. Megan Oakleaf, Value of Academic Libraries: A Comprehensive Research Review and Report, (Chicago, IL: Association of College and Research Libraries, 2010).

9. Bowles-Terry, "Library Instruction and Academic Success," 88.

10. Wong and Cmor, "Measuring Association," 470.

11. Felly Chiteng Kot and Jennifer L. Jones, "The Impact of Library Resource Utilization on Undergraduate Students' Academic Performance: A Propensity Score Matching Design," College and Research Libraries 76 (July 2015): 566-586, accessed April 21, 2017, doi: 10.5860/crl.76.5.566.

12. Ibid., 573.

13. Soria, Fransen, and Nackerud, "Library Use and Undergraduate Student Outcomes."

14. Ibid., 155.

15. Ibid., $160-161$.

16. DeeAnn Allison, "Measuring the Academic Impact of Libraries," portal: Libraries and the Academy 15 (Jan. 2015): 29-40, accessed April 21, 2017, doi: 10.1353/pla.2015.0001.

17. Ibid., 37, emphasis added.

18. Wong \& Cmor, "Measuring Association," 469.

19. Shun Han Rebekah Wong and T. D. Webb, "Uncovering Meaningful Correlation between Student Academic Performance and Library Material Usage," College and Research Libraries 72 (July 2011): 364, accessed April 21, 2017, doi: 10.5860/crl-129.

20 “Undergraduate Graduation Rates," Fact Book, Saint Mary's College, Notre Dame, Indiana, accessed October 10, 2017, https://www.saintmarys.edu/files/2016/10/pg33-UndergradGraduationRates2016.pdf.

21. Bowles-Terry, "Library Instruction and Academic Success," 86; Soria, Fransen, and Nackerud, "Library Use and Undergraduate Student Outcomes," 162. 